\title{
Swanson, John C. 2017. Tangible Belonging: Negotiating Germanness in Twentieth-Century Hungary - Pitt Series in Russian and East European Studies. Pittsburgh, PA: U of Pittsburgh P. 456 pp. Illus.
}

\author{
Reviewed by Virginia L. Lewis*, Northern State University, Aberdeen, South Dakota
}

John C. Swanson is a specialist in Central and Eastern European history. His emphases concern ethnic and minority identity in the context of nationalism, as well as Holocaust studies. Tangible Belonging is not Swanson's first book to address Hungarian history, he also wrote on Hungarian national development in The Remnants of the Habsburg Monarchy: The Shaping of Modern Austria and Hungary 1918-1922 (2001).

In Tangible Belonging, Swanson sets out to analyze and provide a coherent framework for the development of ethnic identity among the German-speaking people who settled in Hungary beginning in the eighteenth century. While Swanson provides much historical background on the earliest Hungarian Germans, or Swabians, his lens is focused on the experiences of this minority over the course of the twentieth century. His thesis posits the notion of "tangible belonging" as the primary way in which the Swabians experienced their relationship with their adoptive homeland. According to the author, tangible belonging refers to how people "understand the place in which they live" (11) and juxtaposes a "centered" form of belonging to abstract "bordered" forms that have resulted from the "homogenizing consequences of modernity" (12). This tangible belonging characterized the Swabians' sense of place in their Hungarian homeland particularly during the interwar period, and it served as a foil against the superimposed forms of belonging introduced by modern national relations that were largely the outcome of the hypernationalist currents that followed the reorganization of Europe as a result of World War I.

Swanson succeeds effectively in using his theoretical arguments to lend transparency to the experiences of Hungarian Germans, who were not merely negotiating their ethnic identity on their own terms, but were increasingly subject to outside influences and manipulation brought to them by the Hungarian government and its agents, on the one hand, and by agents of German national politics, including the German government, on the other. In the absence of disruption from agents outside their communities, the Swabians understood their identity in terms of "tangible" features, including first and foremost the (often widely differing) German dialects

*ginny.lewis@northern.edu

(cc) Br

ULLS D-Serle
New articles in this journal are licensed under a Creative Commons Attribution 4.0 International License.

This journal is published by the University Library System of the University of Pittsburgh as part of its D-Scribe Digital Publishing Program and is cosponsored by the University of Pittsburgh Press 
they spoke, and then their costumes, religion (most were Catholic but many were Lutheran), values, architecture, folk customs, stories, songs, and superstitions.

It is somewhat surprising that, in developing his concept of tangible belonging, Swanson does not incorporate related concepts of emplacement and inhabitancy that have been developed extensively by thinkers ranging from Martin Heidegger to Robert David Sack. Although engagement with such scholarship would have strengthened Swanson's arguments, he nonetheless succeeds in constructing a stand-alone notion of "tangible belonging" that current and future scholars on identity will be referring to for years to come as they further contribute to our understanding of how ethnic and national identities are negotiated. In the case of Swanson's Swabian subjects, their accustomed identity practices met with potent challenges in the wake of the First World War, as the modern Hungarian and German states increasingly succumbed to the need to stake their claims on a minority group whose multi-faceted, organic, "centered" belonging suddenly transformed into an either-or, "bordered" question of whether they were Hungarians on the one hand or Germans on the other.

Through his record of conversations and exchanges with his Hungarian-German interview partners living in Hungary as well as Germany, along with his years-long search for relevant archival documents, Swanson succeeds in painting a detailed portrait of the organizations and individuals who served to facilitate the claims staked by the modernizing agents exercising their influence in Swabian Turkey: journalists who used the press to influence how the Swabians thought of themselves in relation to society, political organizers who used agencies such as the Volksbildungsverein and the Volksbund der Deutschen in Ungarn to exercise influence, educational policies aimed at constraining language use and training through the teaching of majority and minority languages in the schools, and even churches where government loyalty competed with loyalty to the church in priests' efforts to guide their flocks. These powerful influences caused a significant shift away from tangible belonging, effectively disrupting - though not destroying - the earlier humanizing patterns of identity formation characterizing the Hungarian-German minority prior to the advent of modernity.

Tangible Belonging devotes its longest chapter (73 pages) to the shifts in HungarianGerman identity that occurred during the period leading into and through World War II since, as the author observes, these years formed "the peak of the conflict" (232). Thus Chapter Five, entitled "The Volk Triumphant, the Second World War," may prove especially useful for scholars and thinkers on the intersection of nationalism and identity in twentieth-century Europe. But Swanson also portrays effectively the profound and traumatizing disruptions of HungarianGerman identity as a result of the expulsions affecting them in the years following World War II. His study lends additional understanding to the profoundly dehumanizing impact that minority policy as practiced by the Soviet-dominated governments in the late 1940s had on individuals who happened no longer to "fit in" to the nationalizing aims of the governments that ruled over them. In the process of investigating the experiences of the Swabians who were expelled from Hungary during this period, Swanson provides useful analysis, without drawing any simpleminded conclusions, of the relationship between the Hungarian Germans' experiences and the experiences of those who suffered directly during the Holocaust. 
Tangible Belonging is useful reading for anyone interested in the German minority in Hungary, and by extension in German minority groups across Europe. The similarities between the Hungarian Germans and Russian Germans, for example, are many and varied. Beyond this, Swanson develops, in spite of his neglecting to show how his own concept of "tangible belonging" relates to established concepts of inhabitancy and emplacement, a promising approach to understanding minority identity across Europe over the course of modernization and the advance of nationalism that attended it. His study is marked by scrupulous scholarship and research and exhibits great respect for his Hungarian-German informants without whose help he could not have arrived at his many useful conclusions. The book is written in an eminently readable style and, as a result of its topic, contains a wealth of fascinating details regarding the lives of the German peasants who settled in Hungary and enriched the culture there with their customs and contributions both economically and culturally. The illustrations provide another vibrant level of documentation that increases the interest and value of this outstanding study. 